\title{
An unusual case of hip pain after total hip arthroplasty: A case report
}

\author{
András Gömöri, $\mathrm{MD}^{1} \mathbb{D}$, János Gombos, $\mathrm{MD}^{2} \mathbb{D}$, Miklós Papp, $\mathrm{PhD}, \mathrm{MD}^{3} \mathbb{D}$ \\ ${ }^{1}$ Department of Traumatology, County Hospital and University Hospital, Miskolc, Hungary \\ ${ }^{2}$ Nuclear Medicine Laboratory, County Hospital and University Hospital, University of Miskolc Faculty of Health Care, Miskolc, Hungary \\ ${ }^{3}$ Department of Orthopedics, County Hospital and University Hospital, University of Miskolc Faculty of Health Care, Miskolc, Hungary
}

Iliopectineal or iliopsoas bursa is the largest, naturally occurring bursa of the human body. ${ }^{[1-3]}$ It has a central occurrence among the other peri-articular cystic conglomerates and has proximity to the femoral vein and artery. ${ }^{[1]}$ Iliopectineal bursa communicates with the hip joint in 15 to $40 \%$ of patients with osteoarthritis of the hip and, therefore, some authors call it a synovial cyst. $^{[1,3,4]}$ In rare cases, it can grow to surprising sizes with a wide variety of causes. ${ }^{[1,2,5,6]}$ The bursa can reach the extent which can lead to symptoms similar to compartment syndrome, but this case is even rarer. ${ }^{[5,7]}$

In the literature, massive iliopectineal bursa emerging after hip arthroplasty has been described as a peculiar condition. ${ }^{[2,3,8]}$ Herein, we present an unusual case of hip pain after total hip arthroplasty which was diagnosed using new techniques.

Received: November 10, 2020

Accepted: January 14, 2021

Published online: June 11, 2021

Correspondence: András Gömöri, MD. Department of

Traumatology, County Hospital and University Hospital,

3526 Szentpéteri kapu, Miskolc, Hungary.

E-mail: gomoria88@gmail.com

Doi: $10.52312 /$ jdrs.2021.79868

Citation: Gömöri A, Gombos J, Papp M. An unusual case of hip pain after total hip arthroplasty: A case report. Jt Dis Relat Surg 2021;32(2):546-550.

(02021 All right reserved by the Turkish Joint Diseases Foundation

This is an open access article under the terms of the Creative Commons Attribution-NonCommercial License, which permits use, distribution and reproduction in any medium, provided the original work is properly cited and is not used for commercial purposes (http://creativecommons.org/licenses/by-nc/4.0/).

\section{ABSTRACT}

Our goal is to draw attention to the inflammation of the iliopectineal bursa being a rare condition, which can cause lower limb swelling and anterior pain of the hip even years after total hip arthroplasty. A 67-year-old woman was admitted seven years after hip arthroplasty (cemented total endoprosthesis [TEP]) with swelling and feeling of excessive fullness of the lower extremity and with tolerable anterior hip pain. The physical examination and blood tests were non-specific for septic condition. Ultrasound showed a cystic mass in the inguinal region with a direct contact to the common femoral vein. Deep vein thrombosis was excluded. The single-photon emission computed tomography-computed tomography (SPECT-CT) was administered to decide the surgical plan, either making a bursa extirpation or making revision hip arthroplasty. The SPECT-CT excluded the possibility of aseptic loosening. Methylene blue was injected into the bursa intraoperatively which did not enter the strong pseudo-capsule of the joint and, therefore, we did not administer revision of the TEP, and the bursa was extirpated. Two weeks after the operation, the patient had no pain, was able to walk, and the swelling decreased. Four months after surgery, the pain and feeling of fullness disappeared, with minimal lower limb swelling. In conclusion, in case of increasing complaints of patients who left years behind without any problem following total hip arthroplasty, the pathogenic role of the iliopectineal bursa should be taken into account, after excluding more frequent causes such as aseptic loosening or periprosthetic joint infection. As long as we consider about a rare disease, we can find a solution to the patient's complaint sooner.

Keywords: Duplex ultrasound. iliopectineal bursitis, surgery, synovial bursa, total hip arthroplasty.

\section{CASE REPORT}

A 67-year-old woman was admitted seven years after hip arthroplasty with swelling and feeling of excessive fullness of the lower extremity and with tolerable anterior hip pain. After TEP implantation (Metrimed PC; Metrimed Kft, Hódmezővásárhely, 
Hungary) at the orthopedic surgery clinic, the patient attended to routine follow-up visits yearly without any complaints. In her previous examination in the angiology clinic referred by the general practitioner, deep venous thrombosis was suspected on physical examination and color Duplex ultrasound was performed which ruled out deep vein thrombosis and revealed a cystic body affecting the common femoral vein. The patient was, then, referred to the orthopedics clinic.

Her medical history revealed moderate pain in the right inguinal region three months before visiting the general practitioner. The pain was constant and independent of physical activity. Main symptoms were swelling and excessive feeling of fullness of the right extremity. Moderate pain in the right inguinal region was detected at the orthopedic surgery outpatient clinic. The circumference of the right thigh was larger by $3.5 \mathrm{~cm}$ than the contralateral one. In the site of the direct lateral approach, no hyperemia was found, and blood tests did not suggest any infection. Meanwhile, the diagnosis of the iliopectineal bursitis occluding the common femoral vein was already certain. We decided surgical treatment. A written informed consent was obtained from the patient. To tailor the surgical plan (extirpating the bursa on its own or extirpation and TEP revision) anteroposterior and lateral
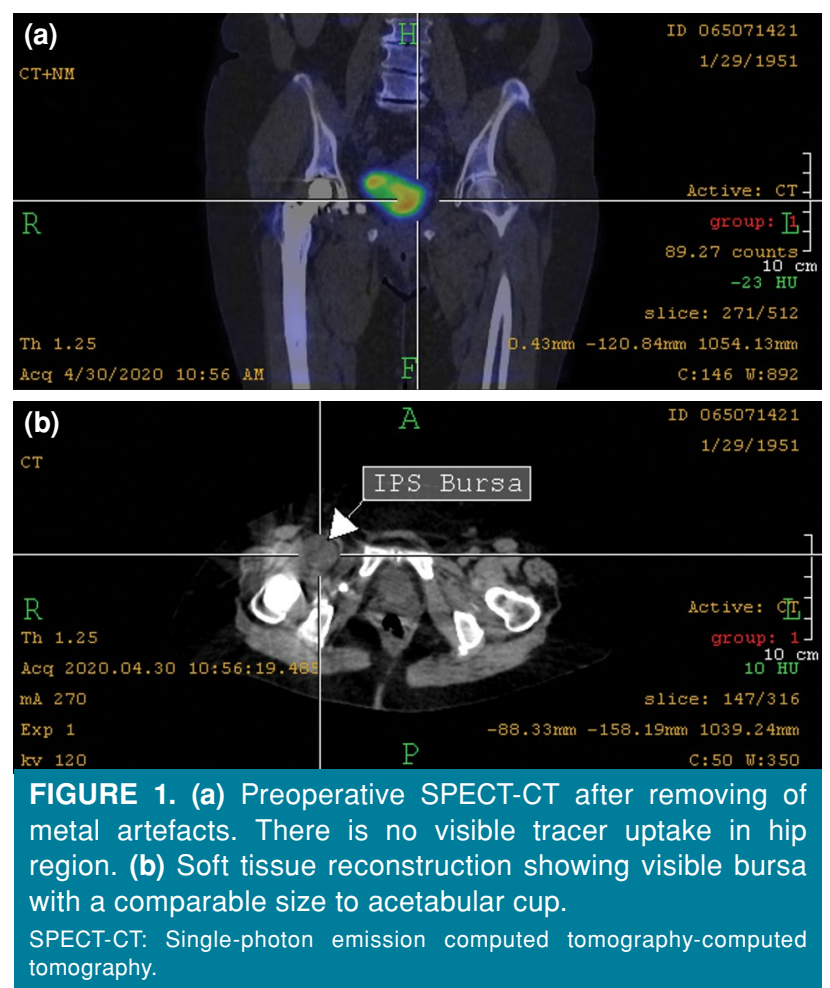

radiographs and single-photon emission computed tomography-computed tomography (SPECT-CT; AnyScan $^{\circledR}$ SC SPECT-CT; MEDISO Medical Imaging Systems, Budapest, Hungary and Tera-Tomo ${ }^{\mathrm{TM}}$ 3D SPECT reconstruction; MEDISO Medical Imaging Systems, Budapest, Hungary) were administered with digital subtraction of metal components (CT reconstruction: filtered back projection-based Tera-Tomo $^{\text {TM }}$ 3D CT with Metal Artifact Correction Module; MEDISO Medical Imaging Systems, Budapest, Hungary). On the radiograph of the hip, a minimal lytic zone was seen on the cranial end of the cup without signs of instability. On the images of the SPECT-CT, no accumulation of the isotopes was found and the bone cement mantle was intact (Figure 1). Repeated ultrasound examination was performed using the Xario ${ }^{\mathrm{TM}}$ device (Toshiba Medical Systems Corp., Tochigi, Japan) targeting the cystic mass. The imaging examinations confirmed our diagnosis, showing a direct contact of the iliopectineal bursa and femoral vein (Figure 2).

Subsequently, surgical procedure was planned. If the methylene blue injected into the bursa did not enter under the pseudo-capsule of the joint, the bursa would have been removed on its own. In case of
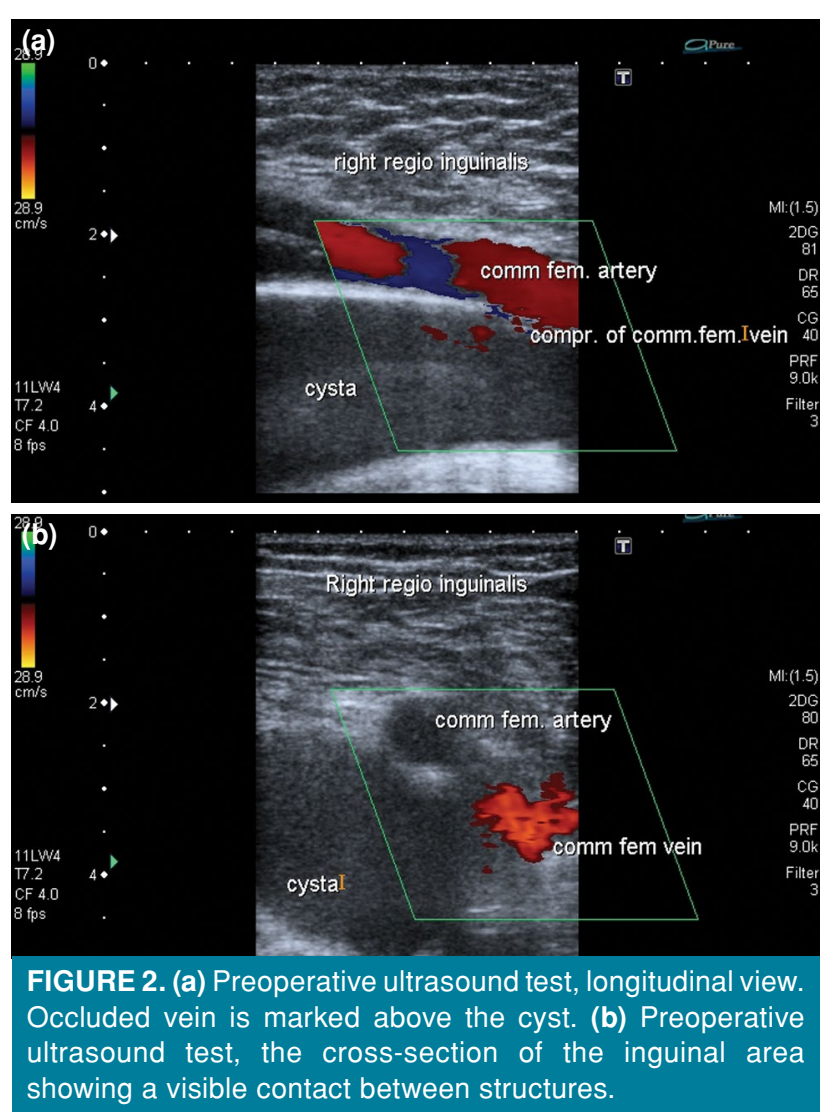


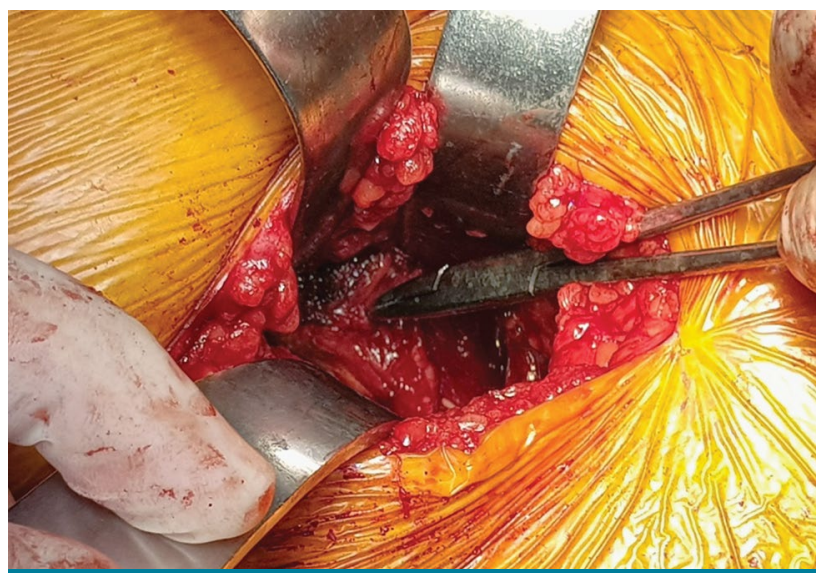

FIGURE 3. Anterior approach of the hip. The cystic mass starts between ventral pseudo-capsule and iliopsoas muscle.

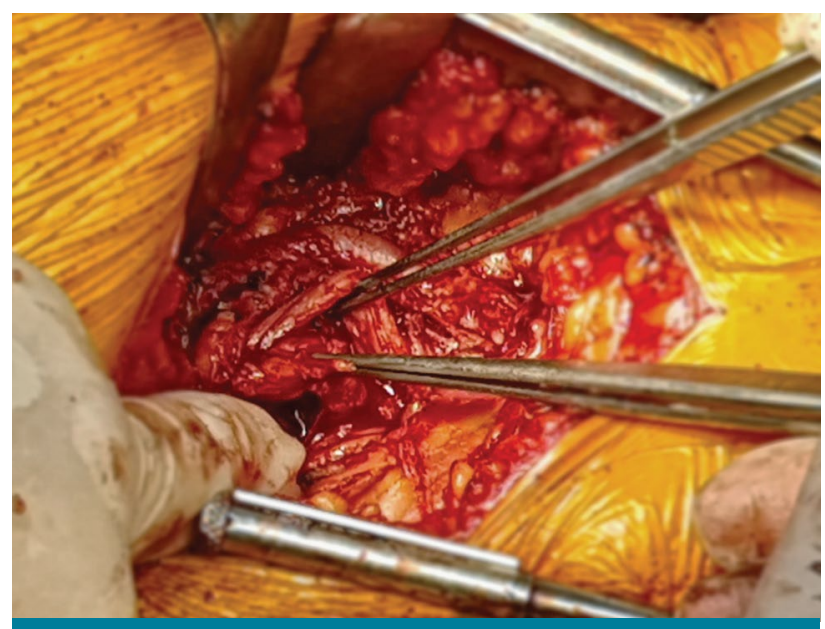

FIGURE 4. Approach for the neurovascular bundle. Forceps, being upper on the picture (closer to the midline in reality), holds vessels, lower forceps grasp wall of the bursa.

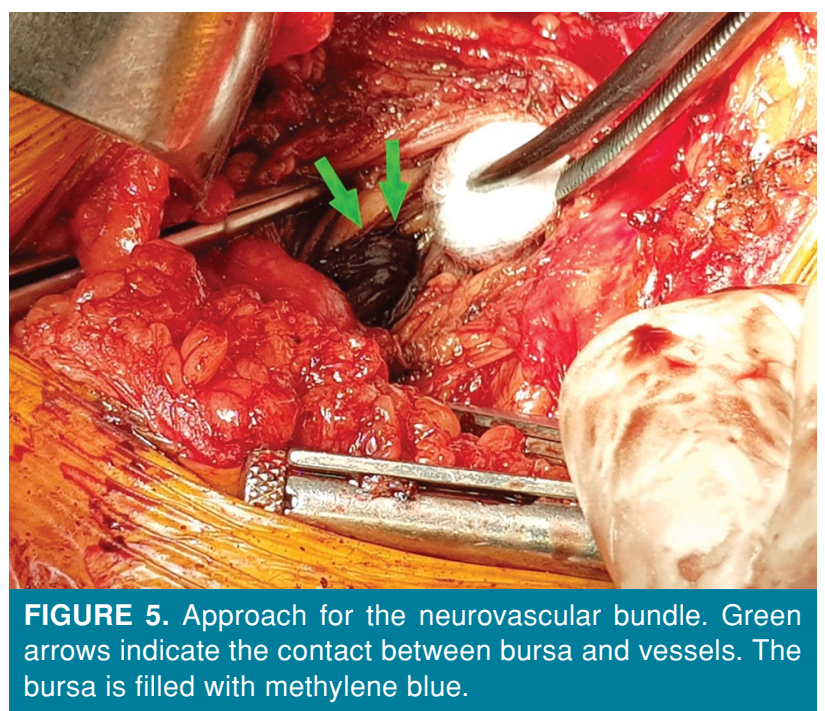

connection between the hip joint and the iliopectineal bursa, extirpation and TEP revision would have been performed. Due to the proximity of the vessels, a vascular surgeon attended to the operation. Regional anaesthesia was used during the procedure. Two incisions were made with special care to the width of the skin bridge between them; the medial end of the bursa was managed through a classical incision for reaching the neurovascular bundle; for the lateral end and to reach the joint, we used the anterior approach of the hip (Figure 3 and 4). We found the bursa laterally between the rectus femoris and iliopsoas muscles, reaching the common femoral vein at its laterodorsal side. Methylene blue was injected into the iliopectineal bursa to ensure whether there was connection with the hip joint. There were no traces of blue color in the region of the joint pseudo-capsule. Using methylene blue, the connection between the bursa and the hip joint was excluded. The contact with the vein was easy to detect (Figure 5). The bursa was removed with blunt technique in one piece. The extracted cystic body was sent to the histological examination. Malignancy was ruled out. After irrigating the wound with saline, it was closed in two layers above a drain.

The patient recovered with full function. Four months after surgery, the pain and feeling of fullness disappeared with minimal constant swelling of the limb. The patient is still under follow-up.

\section{DISCUSSION}

Hip pain is a frequent complaint. In adulthood, the main causes can be arthritis, avascular necrosis, infection, and neoplasms. ${ }^{[9]}$ Following arthroplasty, there is a wide range of causes including aseptic loosening, idiopathic pain, instability, infection, local tissue reaction, pseudotumor formation, polyethylene wear, and other etiologies. ${ }^{[10-12]}$ Swelling of the lower extremity is a frequent complaint, as well. If it is unilateral, the main causes can be deep venous thrombosis, chronic venous insufficiency, and primary lymphedema. ${ }^{[3]}$ Infections and neoplasms should be also considered in the differential diagnosis. ${ }^{[3]}$ More common causes are easy to differentiate: i.e., with radiography, ultrasonography, $\mathrm{CT}$, and monitoring inflammatory laboratory parameters, and most of the aforementioned diseases can be excluded through these methods.

Bursitis can occur with several etiologies including arthritis, osteonecrosis, trauma, infection, overuse, and polyethylene debris. ${ }^{[2,3,5]}$ In the literature, there are only a few cases where bursitis enlargement occurred on a similar scale after hip arthroplasty ${ }^{[2,3,8]}$ 
and all of the authors agreed that the main cause could be the polyethylene debris infiltrating into the bursa.

Yang and Bronson ${ }^{[2]}$ reported an unusual case of cystic mass four years and four months after arthroplasty. Similar to our case, the main symptom was swelling of extremity. Radiography of the hip, photoplethysmography, venogram, and CT were used to locate the soft tissue and to make the diagnosis. Aspiration was also carried out, and neither extirpation nor revision arthroplasty was done. In another report, DeFrang et al. ${ }^{[3]}$ present a case having right leg pain and swelling three years after total hip arthroplasty. Radiography, venous Duplex examination, and CT were used. Partial resection of the cyst and ligation the connection to the joint space was carried out. Lin et al. ${ }^{[8]}$ also reported a similar case. Non-cemented, porous-coated anatomic bipolar hemiarthroplasty was performed of the left hip 11 years ago. The implant functioned well for eight years, at which time the patient began to feel a small mass over the left inguinal region with no other associated symptoms. Radiographs, sonography, and CT were used to find the volumetric wear of the inner bearing of the bipolar cup. Revision was made to convert the hemiarthroplasty to total hip arthroplasty. The cystic body was left in place, after aspirating the fluid and closing the connection to the hip joint.

It seems to have a somewhat relation between the existence of polyethylene wear and the appearing bursitis. Theoretically, the suspected debris can enter the bursa only in $40 \%$ of the population affected with osteoarthritis of the hip ${ }^{[3]}$ and, even if it happens, it does not eliminate other causes. The SPECT-CT is a very sensitive method to detect metabolic activity and can further differentiate between the causes. ${ }^{[10,11]}$ It is also described that, even if SPECT-CT is second-line equipment, the utilization of this tool modifies the management plan in 60 to $70 \%$ of patients. ${ }^{[11]}$ With the combination of ultrasonography and SPECT$\mathrm{CT}$, the formation of pseudotumors is easy to detect. ${ }^{[10,11]}$ In our case, the SPECT-CT was done to tailor the surgical plan. Due to the intact cement mantle and the lack of the increased isotope accumulation on the SPECT-CT image, we opted to extirpate the bursa. The plan would have been modified or confirmed by filling of the bursa with methylene blue. Intraoperatively methylene blue would have alerted us, if there had been some connection between the space of bursa and the joint.
Furthermore, there is an option to use contrast agents with radiography or CT; however, these methods cannot monitor the bone metabolism. ${ }^{[2,3,10,11]}$ Using the SPECT-CT, the communication between the bursa and the joint cannot be confirmed and, therefore, we used a directly visible solution (methylene blue injection) in our case.

We believe that there should be more evidencebased studies to explore the possibilities that lead to the formation of bursitis. If we consider the rarity of the cases, it is a very laborious objective for researchers.

In conclusion, in case of increasing complaints of patients who left years behind without any problems following total hip arthroplasty, the pathogenic role of the iliopectineal bursa should be taken into account, after excluding more frequent causes such as aseptic loosening and periprosthetic joint infection. As long as we consider about a rare disease, we can find a solution to the patient's complaint sooner. Of note, SPECT-CT is relatively new in the orthopedic set-up. Based on our experience, there can be a well-established place for it in the diagnostic array. The ability to link the anatomic region with the bone-metabolism makes decision making easier and safer. The SPECT-CT is able to show whether the cement mantle is intact or not. In the light of these data, we suggest the use of the algorithm of sonography, SPECT-CT, and methylene blue injection in the diagnosis of the iliopectineal bursitis. We believe that our experiences with this rare case provide a valuable guide to other physicians.

\section{Declaration of conflicting interests}

The authors declared no conflicts of interest with respect to the authorship and/or publication of this article.

\section{Funding}

The authors received no financial support for the research and/or authorship of this article.

\section{REFERENCES}

1. Finder JG. Iliopectineal bursitis. Arch Surg 1938;36:519-30.

2. Yang SS, Bronson MJ. Cystic enlargement of the iliopsoas bursa causing venous obstruction as a complication of total hip arthroplasty. A case report. J Arthroplasty 1993;8:657-61.

3. DeFrang RD, Guyer WD, Porter JM, Duwelius PJ. Synovial cyst formation complicating total hip arthroplasty: A case report. Clin Orthop Relat Res 1996;(325):163-7.

4. Colasanti M, Sapienza P, Moroni E, Mosiello G, Postacchini F, di Marzo L. An unusual case of synovial cyst of the hip joint presenting as femoral vein compression and severe lower limb edema. Eur J Vasc Endovasc Surg 2006;32:468-70. 
5. Iwata T, Nozawa S, Ohashi M, Sakai H, Shimizu K. Giant iliopectineal bursitis presenting as neuropathy and severe edema of the lower limb: Case illustration and review of the literature. Clin Rheumatol 2013;32:721-5.

6. Kuroyanagi G, Yamada K, Imaizumi T, Mizutani J, Wada I, Kozawa O, et al. Leg lymphedema caused by iliopectineal bursitis associated with destruction of a rheumatoid hip joint: A case report. Exp Ther Med 2013;6:887-90.

7. Vohra HA, Jones B. Femoral vein compression by iliopsoas bursa: A rare presentation. EJVES Extra 2001;1:53-4.

8. Lin YM, Ho TF, Lee TS. Iliopectineal bursitis complicating hemiarthroplasty: A case report. Clin Orthop Relat Res 2001;(392):366-71.
9. Boya H, Özcan Ö, Araç Ş. Kalça ekleminin “Kimik iliği ödemi sendromu"; olgu sunumu ve literatür derlemesi. Eklem Hastalik Cerrahisi 2004;15:230-4.

10. Tam HH, Bhaludin B, Rahman F, Weller A, Ejindu V, Parthipun A. SPECT-CT in total hip arthroplasty. Clin Radiol 2014;69:82-95.

11. Van den Wyngaert $T$, Paycha F, Strobel K, Kampen WU, Kuwert T, van der Bruggen W, et al. SPECT/CT in postoperative painful hip arthroplasty. Semin Nucl Med 2018;48:425-38.

12. Çimen O, Azboy N, Çatal B, Azboy İ. Assessment of periprosthetic joint infection prevention methods amongst Turkish orthopedic surgeons in total joint replacement: A survey. Jt Dis Relat Surg 2020;31:230-7. 